\title{
SIMULATING PROGRESSIVE DAMAGE OF NOTCHED COMPOSITE LAMINATES WITH VARIOUS LAMINATION SCHEMES
}

\author{
B. MANDAL ${ }^{*}$ and A. CHAKRABARTI \\ Department of Civil Engineering \\ Indian Institute of Technology Roorkee \\ Roorkee-247 667, INDIA \\ E-mails: bibekanandabesu@gmail.com; anupam1965@yahoo.co.uk
}

\begin{abstract}
A three dimensional finite element based progressive damage model has been developed for the failure analysis of notched composite laminates. The material constitutive relations and the progressive damage algorithms are implemented into finite element code ABAQUS using user-defined subroutine UMAT. The existing failure criteria for the composite laminates are modified by including the failure criteria for fiber/matrix shear damage and delamination effects. The proposed numerical model is quite efficient and simple compared to other progressive damage models available in the literature. The efficiency of the present constitutive model and the computational scheme is verified by comparing the simulated results with the results available in the literature. A parametric study has been carried out to investigate the effect of change in lamination scheme on the failure behaviour of notched composite laminates.
\end{abstract}

Key words: damage mechanics, user-defined subroutine, composite laminates, finite element, strength, degradation.

\section{Introduction}

Fiber reinforced plastic composites are widely used materials in many engineering applications, ranging from various sports accessories to advanced ship and aerospace structures. The key reasons behind this popularity are due to their light weight without sacrificing in the strength and good resistance to corrosion and fatigue. For different components of these laminated composite structures, sometimes notches are unavoidable. Local damages may be initiated at an early loading stage in these notched components and can propagate as the load increases. The progressive failure analysis of such notched components is essential to predict their accurate mechanical behaviour under various loading conditions. However, for laminated composites, failure mechanisms are rather complex due to their inhomogeneous and layered configuration. Defects, namely: breakage of fibre, matrix cracking, fibre/matrix de-bonding occurring in a ply, may not cause an immediate collapse but usually accumulate progressively within the composite laminates which leads to the gradual degradation of the material properties.

Finite element (FE) based progressive damage models are already established as very powerful techniques for the damage analysis and prediction of failure strength. Chang and Chang [1] was first to propose an FE based progressive damage model to predict tensile strength of laminated composites containing stress concentrations. Progressive damage by partial discount method was introduced by them. However, their model results in underestimation of failure strength in some cases as pointed out by Icten and Karakuzu [2]. Chang and Lessard [3] extended the previous progressive damage model for investigating the compressive failure strength of laminated composites. Researchers like: Lessard and Shokrieh [4], Shahid and Chang [5], Su et al. [6], Icten and Karakuzu [2] also studied damage accumulation in composite laminates. Several damage models for fiber reinforced plastics have also been published based on the continuum damage mechanics approach by

\footnotetext{
* To whom correspondence should be addressed
} 
Kwon and Liu [7], Camanho et al. [8], Liu and Zheng [9] and Sosa et al. [10] etc. There are numerous papers which have already been reported to predict the failure strength and damage propagation of composite laminates with notches, but only few of them can predict precise results. The reason behind this may be nonavailability of well-established failure criterion and stiffness degradation rules for laminated composites, and therefore, it is acknowledged as an ongoing research area. Also, the reported studies are mainly based on the finite element models using two dimensional (2D) elements. However, to get more accurate results a model using three dimensional (3D) elements is desirable. A finite element model using 3D elements is also essential for thick laminates and for a better representation of damage propagation or, other results through the thickness of the laminate.

In this paper, a finite element based progressive damage model considering 3D solid brick elements has been presented, which can predict the failure load of notched laminated composite plates. The proposed model is suitable for the composite laminates which show brittle failure with some non-linearity but not up to the plastic behaviour. This sort of behaviour is usually noticeable for the laminated composites like: EGlass/Epoxy, commonly used for the heavy engineering application. For the present progressive damage model, a user-defined subroutine UMAT is written considering 3D solid brick element C3D8R [11], available in finite element based software Abaqus 6.12. The authors could not trace any literature on progressive damage analysis of notched composite laminates considering 3D solid brick element. The proposed numerical model can also be used to predict progressive damage of thick laminates due to the use of 3D solid elements. In this proposed model, the existing failure criteria available in the literature on composite laminates have been modified to include the fiber/matrix shear damage and delamination effects. The results generated from the present model agree well with the available results in the literature. The effect of change in the lamination scheme for notched composite laminates has also been studied.

\section{Numerical model}

A progressive damage model using 3D solid elements can predict much better results in terms of accuracy and visualization, rather than a model using 2D SHELL elements. But, unfortunately 3D progressive damage models are not available in the literature on laminated composite materials. In this paper, a progressive damage model has been presented for composite laminates which uses 3D solid elements. The proposed progressive material damage model has been assimilated with the finite element software package Abaqus using user-subroutine UMAT. The UMAT is developed for the 3D solid brick element C3D8R, available in Abaqus. The composite laminas have been modeled as an orthotropic material with a full $6 \times 6$ constitutive matrix as

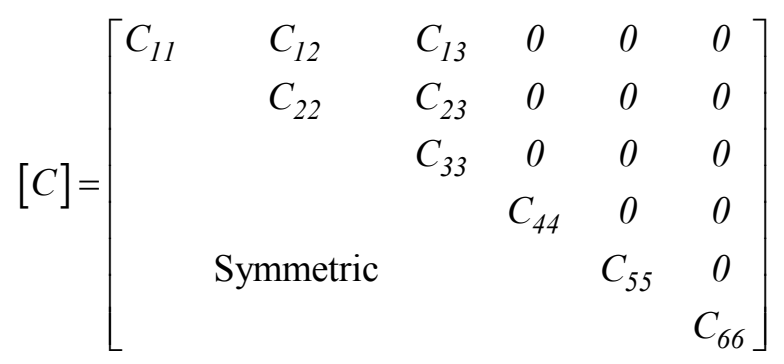

where the components of the elastic constitutive matrix [C], can be described as

$$
C_{i i}=\frac{E_{i i} / T_{1}}{l-v_{j k} v_{k j}} \rightarrow \quad i, j, k=1 \quad \text { to } \quad 3 ; \quad i \neq j \neq k,
$$




$$
\begin{aligned}
& C_{i j}=\frac{E_{i i} / T_{1}}{v_{j i}+v_{j k} v_{k i}} \rightarrow \quad i, j, k=1 \quad \text { to } 3 ; \quad i \neq j \neq k ; \quad i<j, \\
& C_{44}=G_{12}, \quad C_{55}=G_{13}, \quad C_{66}=G_{23} \quad \text { and, } \\
& T_{1}=1-v_{12} v_{21}-v_{23} v_{32}-v_{13} v_{31}-v_{12} v_{23} v_{31}-v_{23} v_{13} v_{21} .
\end{aligned}
$$

Using user-subroutine UMAT, it is possible to develop a failure model considering different types of damages. In the present progressive damage model, material properties are degraded according to type of failure. For example, if a fibre failure occurred, longitudinal Young's modulus, $E_{11}$, is discounted for the loss of stiffness in that direction, while the transverse Young's moduli, $E_{22}$ and $E_{33}$, are considered to be unaffected and are kept unchanged. So, for performing progressive failure analysis of composite laminates, it is mandatory that the failure modes are to be evaluated precisely so that material properties can be degraded appropriately. A well-known failure theory for laminated composite materials developed by Hashin [12] that can predict failure mode has been implemented after incorporating the effects of fiber/matrix shear damage and delamination in the present program.

\subsection{Failure criterion}

To determine the failure of a material point of the composite laminate, the failure criteria by Hashin [12] have been considered here along with delamination failure criteria by Lessard and Shokrieh [4] and fiber/matrix shear failure criteria by Naderi and Maligno [13]. The failure criteria considered here are as follows:

Tensile fibre failure, $\sigma_{11}>0$

$$
\frac{\sigma_{11}^{2}}{X_{t}^{2}}+\frac{\sigma_{12}^{2}+\sigma_{13}^{2}}{S_{12}^{2}}=1
$$

Compressive fibre failure, $\sigma_{11}<0$

$$
\sigma_{11}=-X_{c}
$$

Tensile matrix failure, $\sigma_{22}+\sigma_{33}>0$

$$
\frac{\left(\sigma_{22}+\sigma_{33}\right)^{2}}{Y_{t}^{2}}+\frac{\left(\sigma_{23}^{2}-\sigma_{22} \sigma_{33}\right)}{S_{23}^{2}}+\frac{\left(\sigma_{12}^{2}+\sigma_{13}^{2}\right)}{S_{12}^{2}}=1
$$

Compressive matrix failure, $\sigma_{22}+\sigma_{33}<0$

$$
\frac{\left(\sigma_{22}+\sigma_{33}\right)}{Y_{c}}\left\{\left(\frac{Y_{c}}{2 S_{23}}\right)^{2}-1\right\}+\frac{\left(\sigma_{22}+\sigma_{33}\right)^{2}}{4 S_{23}^{2}}+\frac{\left(\sigma_{23}^{2}-\sigma_{22} \sigma_{33}\right)}{S_{23}^{2}}+\frac{\left(\sigma_{12}^{2}+\sigma_{13}^{2}\right)}{S_{12}^{2}}=1 .
$$

- $\quad$ Fibre/matrix shear failure 


$$
\frac{\sigma_{11}^{2}}{X_{c}^{2}}+\frac{\sigma_{12}^{2}}{S_{12}^{2}}+\frac{\sigma_{13}^{2}}{S_{13}^{2}}=1
$$

- Delamination tension/compression failure

$$
\left(\frac{\sigma_{33}}{Z_{r}}\right)^{2}+\left(\frac{\sigma_{13}}{S_{13}}\right)^{2}+\left(\frac{\sigma_{23}}{S_{23}}\right)^{2}=1 .
$$

Solution-dependent state variables (SDVs) have been used to store the calculated failure indexes of each material point at each increment to keep track of the failure propagation. The plot of these SDVs can easily produce a visual representation of failure propagation of various failure indexes using Abaqus postprocessor.

\subsection{Stiffness discount strategy}

The stiffness discount strategy used in the present model is considered as in the direction of failure. The adopted discount strategy is quite simple and can be applied for any type of laminated composite material. The stiffness of a material point has been reduced near to zero at the failed direction. Therefore, the FE model should contain sufficient number of elements along the damage path which can be ensured by convergence study corresponding to different mesh sizes. However, this is really not going to be a problem with the use of modern computers. For example, the solution time taken for a typical problem (sec 3.3, laminate L16) of notched composite plate containing 8320 elements was only $175 \mathrm{~s}$. The simulation was carried out on a workstation with $2.8 \mathrm{GHz}$ (12 CPUs) processor and $48 \mathrm{~GB}$ RAM.

The correlative elastic constants (ECs) have been discounted by multiplying with a very small value $(c)$, if failure occurred in one direction. To avoid numerical instability during the analysis, the value of ' $c$ ' is considered as a very small value other than zero. The material properties for a material point has been discounted when failure is initiated at any time increment and stored for the analysis at the next increment. The discount strategies considered in the present formulation are presented below

- Tensile fibre failure: $E_{11}=c . E_{11}^{0}, \quad G_{12}=c . G_{12}^{0}, G_{13}=c . G_{13}^{0}$.

- $\quad$ Compressive fibre failure: $E_{11}=c . E_{11}^{0}, G_{12}=c . G_{12}^{0}, G_{13}=c . G_{13}^{0}, G_{23}=c . G_{23}^{0}$.

- Tensile/Compressive fibre failure: $E_{22}=c . E_{22}^{0}, E_{33}=c . E_{33}^{0}, G_{23}=c . G_{23}^{0}$.

- $\quad$ Fibre/matrix shear failure: $G_{12}=c . G_{12}^{0}$.

- Delamination tension/compression failure: $E_{33}=c . E_{33}^{0}, G_{13}=c . G_{13}^{0}, G_{23}=c . G_{23}^{0}$

where, superscript ' $O$ ' denotes the initial undamaged material constant value. The flowchart of the user subroutine UMAT is as shown in Fig.1. 


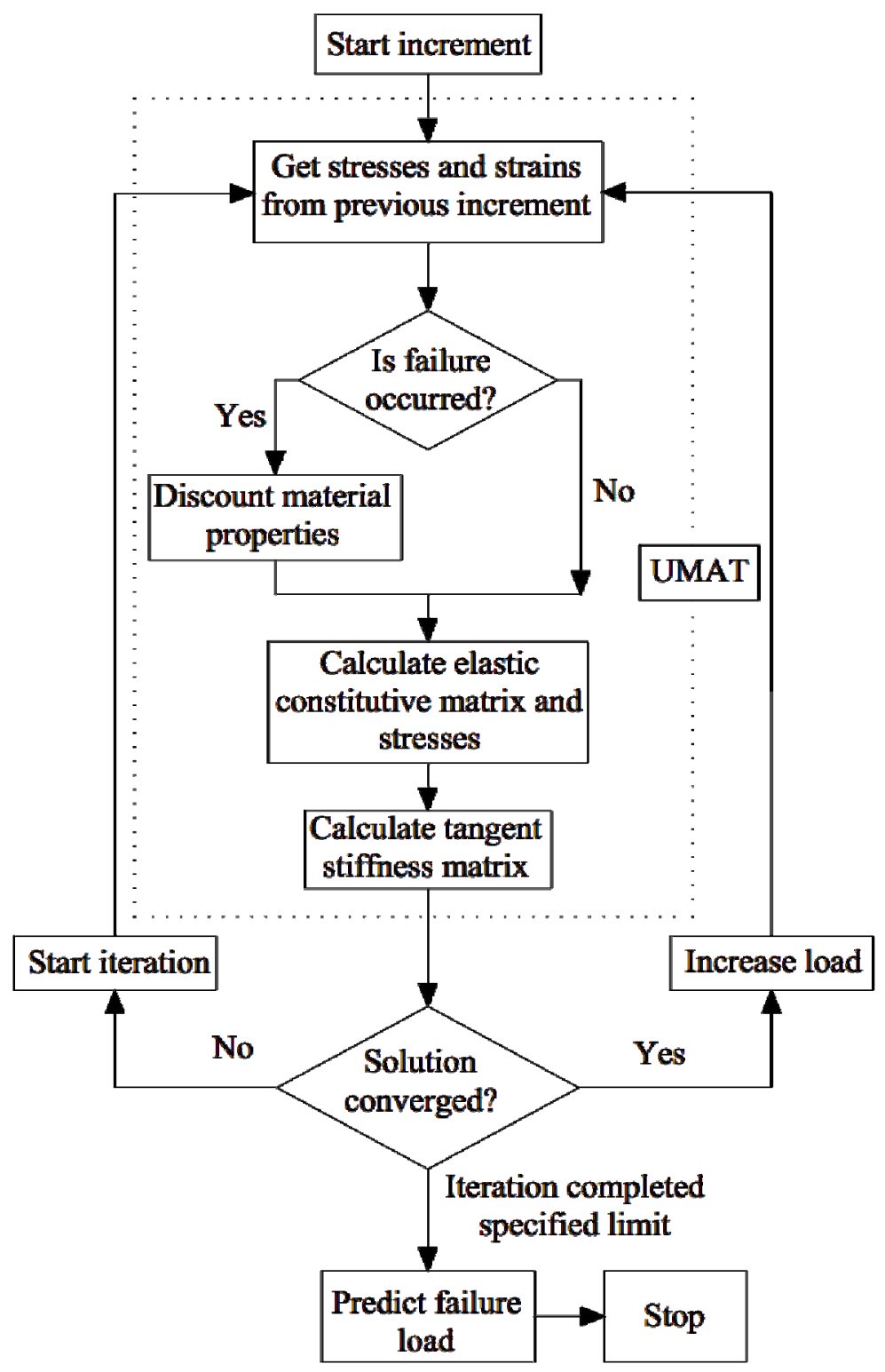

Fig.1. Flow chart of the user subroutine UMAT.

\section{Results}

The accuracy as well as the efficiency of the present numerical model has been verified by comparing the simulated results with the experimental and numerical results available in the literature. Progressive damage analysis of two laminated plates, without/with a blunt notch, have been performed using the present numerical model for this purpose. A parametric study of progressive damage has been presented to study the effect of change in the lamination scheme, on the failure behavior of laminated composite plates.

\subsection{Progressive failure analysis of IM7/5250-4 laminates}

Progressive damage analysis has been performed on IM7/5250-4 composite laminates subjected to uniaxial tensile loading, considering three different types of lamination schemes, namely: S1, S2 and S3 as shown in Tab.1. All the laminates are considered to have length $(L)$ of $76.2 \mathrm{~mm}$. The width $(W)$ of the laminate 
$\mathrm{S} 1$ and $\mathrm{S} 2$ is $25.4 \mathrm{~mm}$ and for laminate $\mathrm{S} 3$ the width is $31.75 \mathrm{~mm}$. All the three laminates consist of laminas of thickness $0.132 \mathrm{~mm}$. The material properties for the IM7/5250-4 composite are presented in Tab.2 and Tab.3.

Table 1. Lamination scheme and ultimate load values.

\begin{tabular}{llll}
\hline \multirow{2}{*}{ Laminate } & \multirow{2}{*}{ Lamination scheme } & \multicolumn{2}{c}{ Failure load $(\mathrm{kN})$} \\
\cline { 3 - 4 } & & $\begin{array}{l}\text { Experimental, } \\
\text { Reddy } \text { et } \text { al. }[14]\end{array}$ & $\begin{array}{l}\text { Present } \\
\text { simulation }\end{array}$ \\
\hline S1 & {$[45 / 90 /-45 / 0]_{3 s}$} & 78.822 & 79.97 \\
\hline S2 & {$\left[45 / 90 /-45 / 0_{3} /-45 / 0_{3} / 45 / 0\right]_{s}$} & 123.038 & 137.86 \\
\hline S3 & {$[45 / 90 /-45 / 45 /-45 / 0 / 45 /-45 / 45 /-45] \mathrm{s}$} & 39.260 & 44.44 \\
\hline
\end{tabular}

Table 2. Material properties of IM7/5250-4.

\begin{tabular}{llllll}
\hline$E_{1}(\mathrm{GPa})$ & $E_{2}(\mathrm{GPa})$ & $G_{12}(\mathrm{GPa})$ & $G_{23}(\mathrm{GPa})$ & $v_{12}$ & $v_{23}$ \\
\hline 161.337 & 9.653 & 5.998 & 3.378 & 0.34 & 0.49 \\
\hline
\end{tabular}

Table 3. Material strength (MPa) data for IM7/5250-4.

\begin{tabular}{llllll}
\hline$X_{t}$ & $X_{c}$ & $Y_{t}$ & $Y_{c}$ & $S_{12}$ & $S_{23}$ \\
\hline 2709.64 & 1075.582 & 64.535 & 258.553 & 92.39 & 67.5686 \\
\hline
\end{tabular}

The load vs displacement plots from the present simulation and by Reddy et al. [14], for the laminate S1 and S2 are shown in Fig.2 and Fig.3, respectively. From these figures it is evident that the present load vs displacement curves matches very well with the results published in the literature. Although, Tab.1 shows that the present numerical model predicts slightly higher strength for some cases as compared to the experimental results, which is quite common and expected due to some deviations during sample manufacturing and experiments.

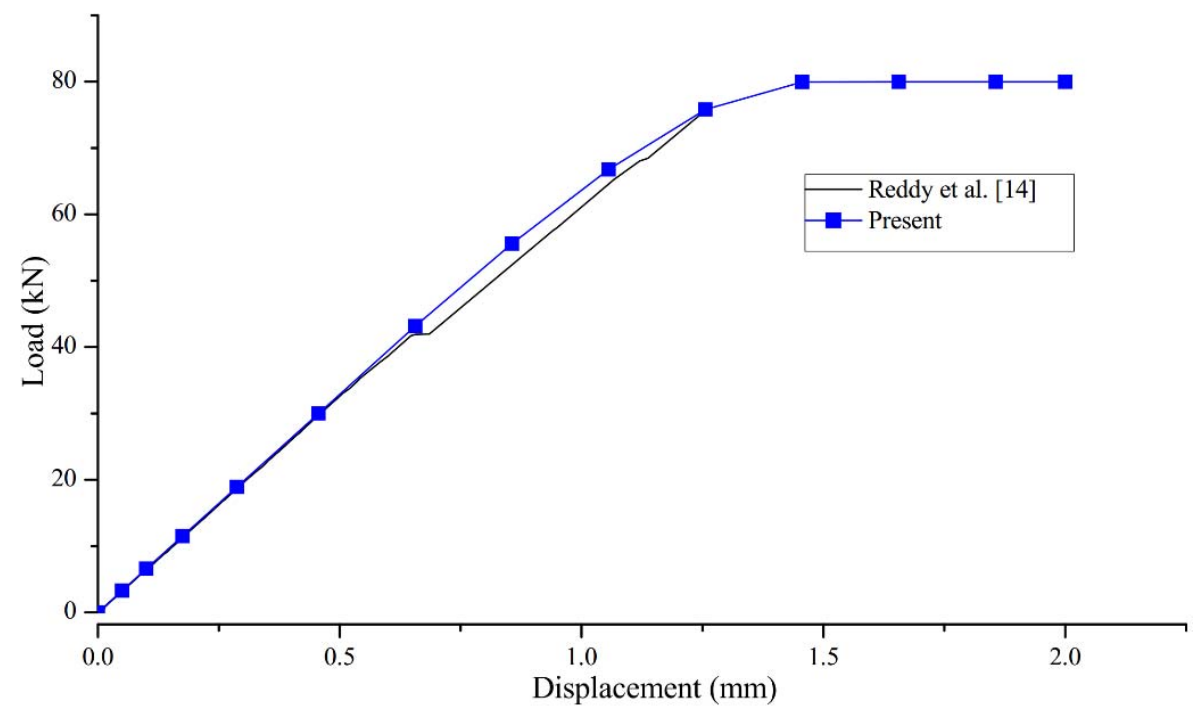

Fig.2. Load vs displacement plot for laminate S1. 


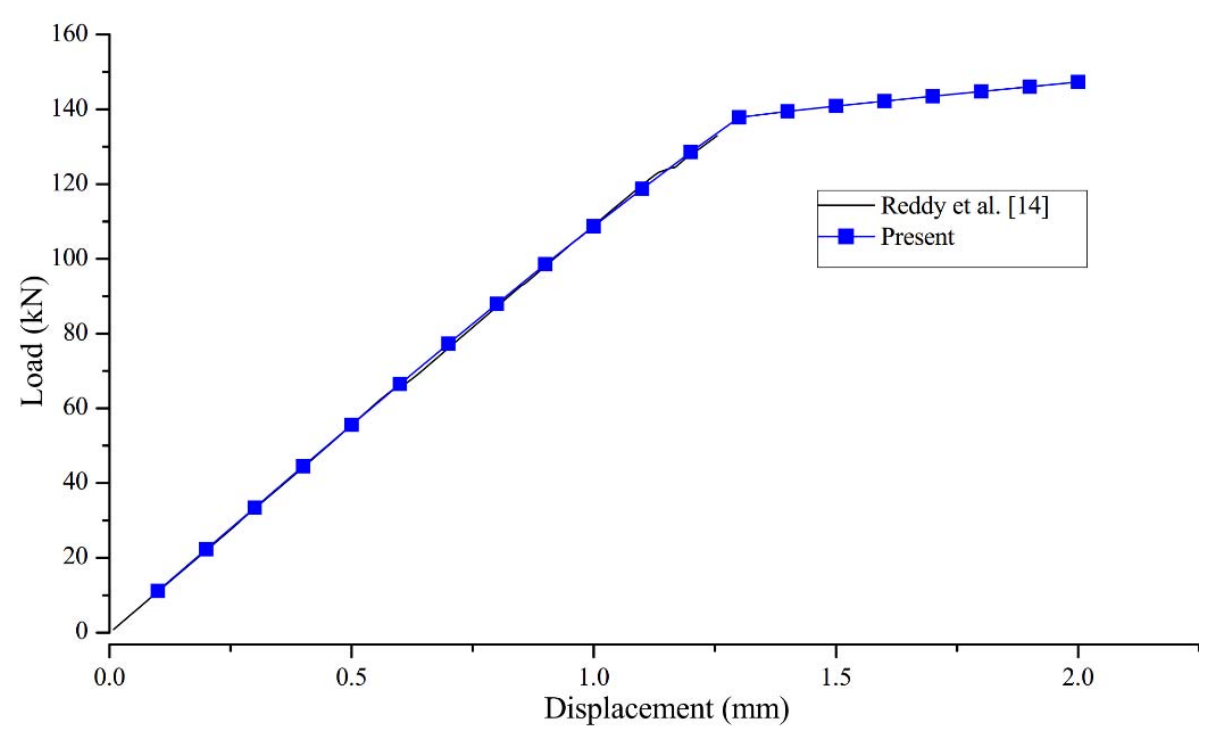

Fig.3. Load vs displacement plot for laminate S2.

\subsection{Progressive failure analysis of notched AS4/PEEK composite laminates}

The efficiency of the constitutive model and the computational scheme is further verified by simulating the progressive damage of AS4/PEEK composite laminates comprising a central through hole, subjected to inplane uniaxial tensile loading. The geometry of the laminate is shown in Fig.4. Each laminate has length $(L)$ of $100 \mathrm{~mm}$, width $(W)$ of $20 \mathrm{~mm}$ and thickness $(t)$ of $2 \mathrm{~mm}$. The diameters of the holes $(D)$ are $2 \mathrm{~mm}, 5 \mathrm{~mm}$ and 10 $\mathrm{mm}$.

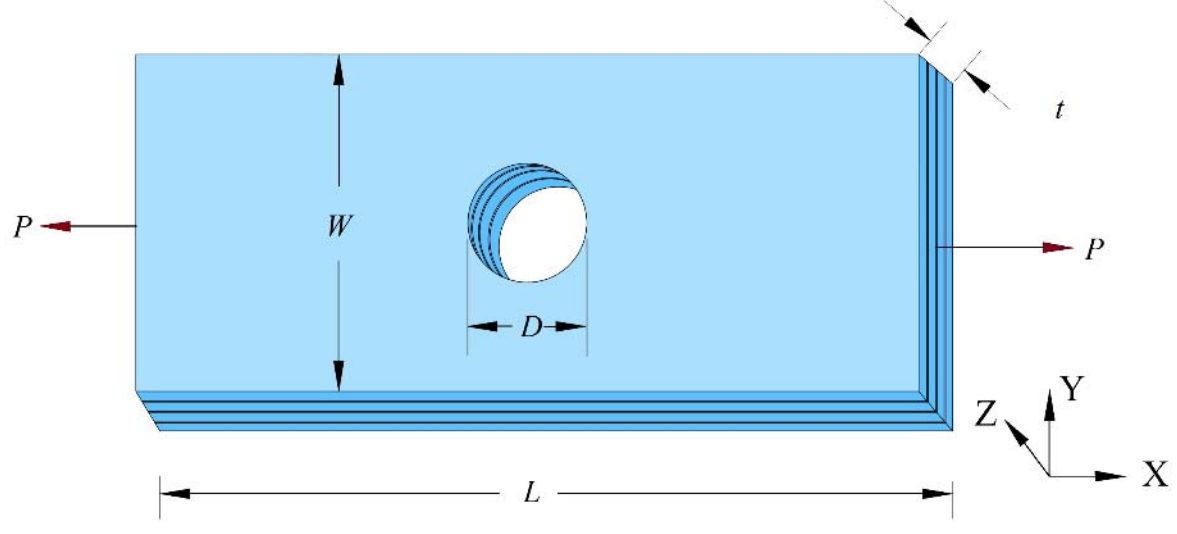

Fig.4. Geometry of the composite laminate.

The laminates are composed of eight layers of equal thickness lamina with the lamination scheme $[0 / 45 / 90 /-45]_{2 \mathrm{~s}}$. The material stiffness and strength properties considered for the analysis are shown in Tab.4 and Tab.5, which are taken from Chen et al. [15].

Table 4. Material properties of AS4/PEEK.

\begin{tabular}{llllll}
\hline$E_{1}(\mathrm{GPa})$ & $E_{2}(\mathrm{GPa})$ & $G_{12}(\mathrm{GPa})$ & $G_{23}(\mathrm{GPa})$ & $v_{12}$ & $v_{23}$ \\
\hline 127.6 & 10.3 & 6.0 & 3.7 & 0.32 & 0.45 \\
\hline
\end{tabular}


Table 5. Material strength (MPa) data for AS4/PEEK.

\begin{tabular}{llllll}
\hline$X_{t}$ & $X_{c}$ & $Y_{t}$ & $Y_{c}$ & $S_{12}$ & $S_{23}$ \\
\hline 2023.0 & 1234.0 & 92.7 & 176.0 & 82.6 & 82.6 \\
\hline
\end{tabular}

Figure 5 shows the present finite element model for the laminated plate with the hole diameter of $5 \mathrm{~mm}$. The estimated results are presented in Tab.6, which are found to be in good agreement with the reported results in the literature.

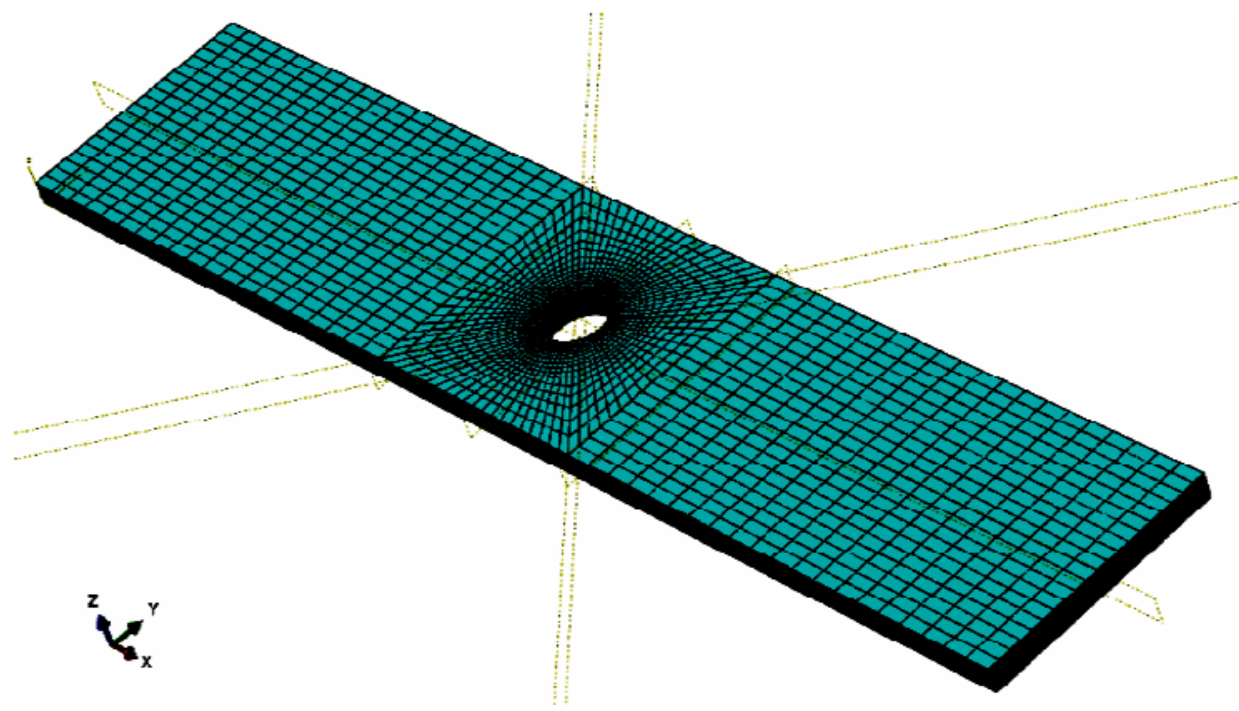

Fig.5. Finite element model of the laminate.

Table 6. Ultimate load values for the AS4/PEEK laminates with different size of hole.

\begin{tabular}{lll}
\hline Hole diameter & $\begin{array}{l}\text { Chen et al. }[15]- \\
\text { continuum shell model }(\mathrm{kN})\end{array}$ & $\begin{array}{l}\text { Present } \\
(\mathrm{kN})\end{array}$ \\
\hline $2 \mathrm{~mm}$ & 28.836 & 27.287 \\
\hline $5 \mathrm{~mm}$ & 23.19 & 22.493 \\
\hline $10 \mathrm{~mm}$ & 14.99 & 14.701 \\
\hline
\end{tabular}

\subsection{Parametric study}

A parametric study has been carried out for the progressive damage simulations of notched EGlass/Epoxy composite laminates composed of sixteen layers with various lamination schemes. Each laminate contains a central through hole of diameter $(D) 5 \mathrm{~mm}$ and has a length $(L)$ of $100 \mathrm{~mm}$, width $(W)$ of $20 \mathrm{~mm}$ and thickness $(t)$ of $2 \mathrm{~mm}$. The material properties considered here are taken from Lian and Yao [16], presented in Tab.7 and Tab.8. 
Table 7. Material properties of E-Glass/Epoxy.

\begin{tabular}{llllll}
\hline$E_{1}(\mathrm{GPa})$ & $E_{2}(\mathrm{GPa})$ & $G_{12}(\mathrm{GPa})$ & $G_{23}(\mathrm{GPa})$ & $v_{12}$ & $v_{23}$ \\
\hline 42.0 & 11.3 & 11.3 & 4.5 & 4.0 & 4.5 \\
\hline
\end{tabular}

Table 8. Material strength (MPa) data for E-Glass/Epoxy.

\begin{tabular}{llllll}
\hline$X_{t}$ & $X_{c}$ & $Y_{t}$ & $Y_{c}$ & $S_{12}$ & $S_{23}$ \\
\hline 900 & 900 & 50 & 140 & 72 & 72 \\
\hline
\end{tabular}

In total, twenty types of lamination schemes have been considered for the present simulation, including different types of unidirectional laminates, cross-ply laminates, quasi-isotropic laminates etc. The effect of percentage of zero degree laminas has also been studied in this paper. The propagation of failure in three dimensions has been presented for some typical cases. Charts are provided for a comparison of the ultimate failure load and the maximum deflection for different lamination schemes. All the results of the present simulation are presented in Tab.9 to Tab.11.

Tensile loading in one axial direction has been applied to the laminates. As expected, the failure load greatly depends on the $\%$ of $0^{\circ}$ laminas. The failure load vs $\%$ of $0^{\circ}$ laminas is shown in Fig.6. The effect of the presence of $45^{\circ}$ and $90^{\circ}$ laminas are visible in this figure when the \% of of $0^{\circ}$ laminas are less than $37.5 \%$. It can also be noted that when all $0^{\circ}, 45^{\circ}$ and $90^{\circ}$ laminas are distributed across the thickness in the same proportion, the failure load is also almost same for all these laminates due to the same stiffness in axial direction.

Table 9. Results for the unidirectional laminates, $[ \pm 45 / \pm 45]_{2 \mathrm{~s}}$ and cross-ply laminates from the parametric study.

\begin{tabular}{|c|c|c|c|c|}
\hline \multicolumn{5}{|c|}{ Unidirectional laminates } \\
\hline $\begin{array}{l}\text { Lamination } \\
\text { ID }\end{array}$ & Lamination scheme & Failure load $(\mathrm{kN})$ & $\begin{array}{l}\text { Displacement at } \\
\text { failure }(\mathrm{mm})\end{array}$ & $\begin{array}{l}\% \text { of } 0^{\circ}, \pm 45^{\circ} \text { anc } \\
90^{\circ} \text { lamina }\end{array}$ \\
\hline L1 & {$\left[0_{16}\right]$} & 25.586 & 1.865 & $100 / 0 / 0$ \\
\hline $\mathrm{L} 2$ & {$\left[90_{16}\right]$} & 1.907 & 0.515 & $0 / 0 / 100$ \\
\hline \multicolumn{5}{|c|}{ Laminate $[ \pm 45 / \pm 45]_{2 \mathrm{~s}}$} \\
\hline $\begin{array}{l}\text { Lamination } \\
\text { ID }\end{array}$ & Lamination scheme & $\begin{array}{l}\text { Failure load } \\
(\mathrm{kN})\end{array}$ & $\begin{array}{l}\text { Displacement at } \\
\text { failure }(\mathrm{mm})\end{array}$ & $\begin{array}{l}\% \text { of } 0^{\circ}, \pm 45^{\circ} \text { anc } \\
90^{\circ} \text { lamina }\end{array}$ \\
\hline L3 & {$[ \pm 45 / \pm 45]_{2 \mathrm{~s}}$} & 4.518 & 0.865 & $0 / 100 / 0$ \\
\hline \multicolumn{5}{|c|}{ Cross-ply laminates } \\
\hline Lamination ID & Lamination scheme & $\begin{array}{l}\text { Failure load } \\
(\mathrm{kN})\end{array}$ & $\begin{array}{l}\text { Displacement at } \\
\text { failure }(\mathrm{mm})\end{array}$ & $\begin{array}{l}\% \text { of } 0^{\circ}, \pm 45^{\circ} \text { anc } \\
90^{\circ} \text { lamina }\end{array}$ \\
\hline L4 & {$[0 / 90 / 90 / 0]_{2 \mathrm{~s}}$} & 14.252 & 1.715 & $50 / 0 / 50$ \\
\hline L5 & {$[0 / 90]_{4 \mathrm{~s}}$} & 14.277 & 1.715 & $50 / 0 / 50$ \\
\hline L6 & {$\left[\left(0_{3} / 90_{2} / 0_{3}\right]_{\mathrm{s}}\right.$} & 20.346 & 1.815 & $75 / 0 / 25$ \\
\hline L7 & {$\left[\left(90_{3} / 0_{2} / 90_{3}\right]_{\mathrm{s}}\right.$} & 7.980 & 1.665 & $25 / 0 / 75$ \\
\hline
\end{tabular}


Table 10. Results for the quasi-isotropic and zero-dominated laminates.

\begin{tabular}{|c|c|c|c|c|}
\hline \multicolumn{5}{|c|}{ Quasi-isotropic laminates } \\
\hline Lamination ID & Lamination scheme & $\begin{array}{l}\text { Failure load } \\
(\mathrm{kN})\end{array}$ & $\begin{array}{l}\text { Displacement at } \\
\text { failure }(\mathrm{mm})\end{array}$ & $\begin{array}{l}\% \text { of } 0^{\circ}, \pm 45^{\circ} \text { and } \\
90^{\circ} \text { lamina }\end{array}$ \\
\hline L8 & {$[0 / 45 / 90 /-45]_{2 \mathrm{~s}}$} & 10.357 & 1.565 & $25 / 50 / 25$ \\
\hline L9 & {$\left[0_{2} / 45_{2} / 90_{2} /-45_{2}\right]_{\mathrm{s}}$} & 10.359 & 1.565 & $25 / 50 / 25$ \\
\hline L10 & {$[45 / 90 /-45 / 0]_{2 \mathrm{~s}}$} & 10.356 & 1.565 & $25 / 50 / 25$ \\
\hline L11 & {$[45 / 0 /-45 / 90]_{2 \mathrm{~s}}$} & 10.354 & 1.565 & $25 / 50 / 25$ \\
\hline \multicolumn{5}{|c|}{ Zero-dominated laminates } \\
\hline Lamination ID & Lamination scheme & $\begin{array}{l}\text { Failure load } \\
(\mathrm{kN})\end{array}$ & $\begin{array}{l}\text { Displacement at } \\
\text { failure }(\mathrm{mm})\end{array}$ & $\begin{array}{l}\% \text { of } 0^{\circ}, \pm 45^{\circ} \text { and } \\
90^{\circ} \text { lamina }\end{array}$ \\
\hline L12 & {$\left[0_{2} / 45 / 90\right]_{2 \mathrm{~s}}$} & 14.533 & 1.615 & $50 / 25 / 25$ \\
\hline L13 & {$\left[0_{3} / 45\right]_{2 \mathrm{~s}}$} & 20.369 & 1.715 & $75 / 25 / 0$ \\
\hline L14 & {$\left[45 / 0_{3}\right]_{2 \mathrm{~s}}$} & 20.365 & 1.715 & $75 / 25 / 0$ \\
\hline
\end{tabular}

Table 11. Results for other laminates from the parametric study.

\begin{tabular}{lllll}
\hline Lamination ID & $\begin{array}{l}\text { Lamination } \\
\text { scheme }\end{array}$ & $\begin{array}{l}\text { Failure load } \\
(\mathrm{kN})\end{array}$ & $\begin{array}{l}\text { Displacement at } \\
\text { failure }(\mathrm{mm})\end{array}$ & $\begin{array}{l}\% \text { of } 0^{\circ}, \pm 45^{\circ} \text { and } \\
90^{\circ} \text { lamina }\end{array}$ \\
\hline L15 & {$\left[45 / 90_{3}\right]_{2 \mathrm{~s}}$} & 2.761 & 0.915 & $0 / 25 / 75$ \\
\hline L16 & {$\left[0 / 45_{2} / 90_{3} /-45_{2}\right]_{\mathrm{s}}$} & 7.379 & 1.465 & $12.5 / 50 / 37.5$ \\
\hline L17 & {$\left[0 / 45_{3} / 90 /-45_{3}\right]_{\mathrm{s}}$} & 7.722 & 1.365 & $12.5 / 75 / 12.5$ \\
\hline L18 & {$\left[(0 / 90)_{3} / 45 /-45\right]_{\mathrm{s}}$} & 12.425 & 1.665 & $37.5 / 25 / 37.5$ \\
\hline L19 & {$\left[0_{3} / 45_{2} / 90 /-45_{2}\right]_{\mathrm{s}}$} & 13.22 & 1.665 & $37.5 / 50 / 12.5$ \\
\hline L20 & {$\left[45_{2} / 0_{2} /-45 / 0 / 45_{2}\right]_{\mathrm{s}}$} & 12.578 & 1.615 & $37.5 / 62.5 / 0$ \\
\hline
\end{tabular}

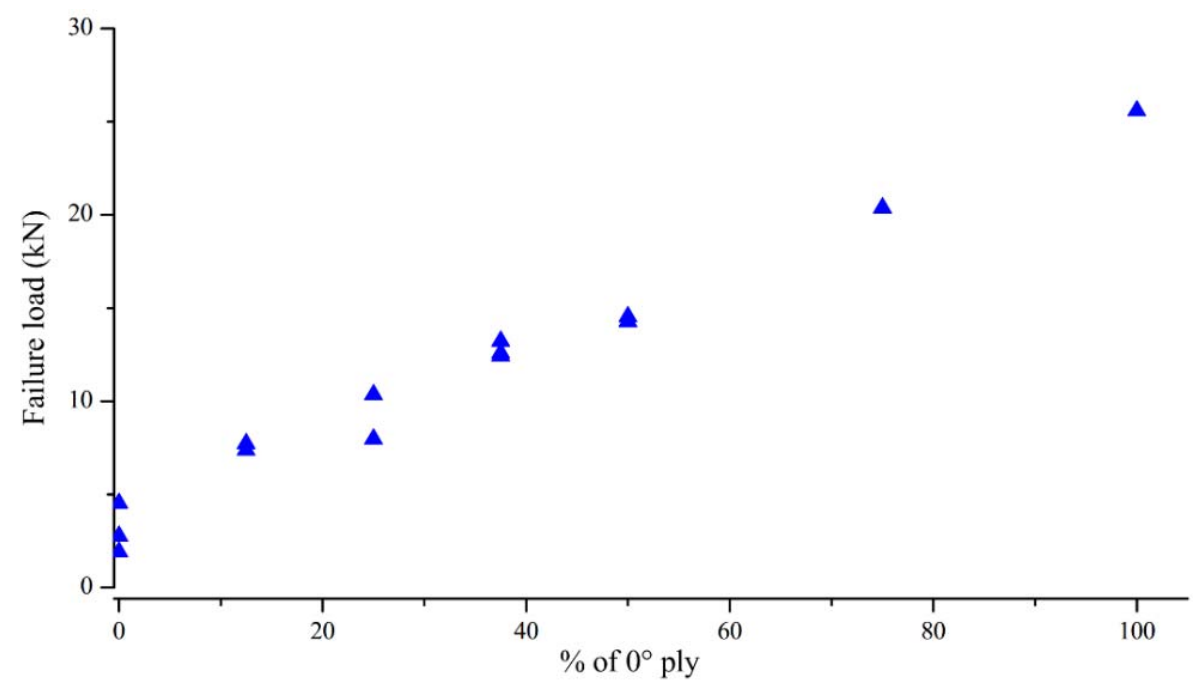

Fig.6. Variation of failure load with $\%$ of $0^{\circ}$ laminas. 
Generally, deflection at failure is found to be between $1.6 \mathrm{~mm}$ to $1.9 \mathrm{~mm}$ for the laminates with $25 \%$ or more $0^{\circ}$ laminas, which is clearly visible from Fig.7. So, it can be concluded that the displacement at failure does not depend too much on the lamination scheme as compared to the failure load when about $25 \%$ of laminas with fibers are in loading direction. We can also expect that the laminate will definitely fail, when the maximum axial strain attains a value of 0.019 , which has been found as a maximum value from this parametric study.

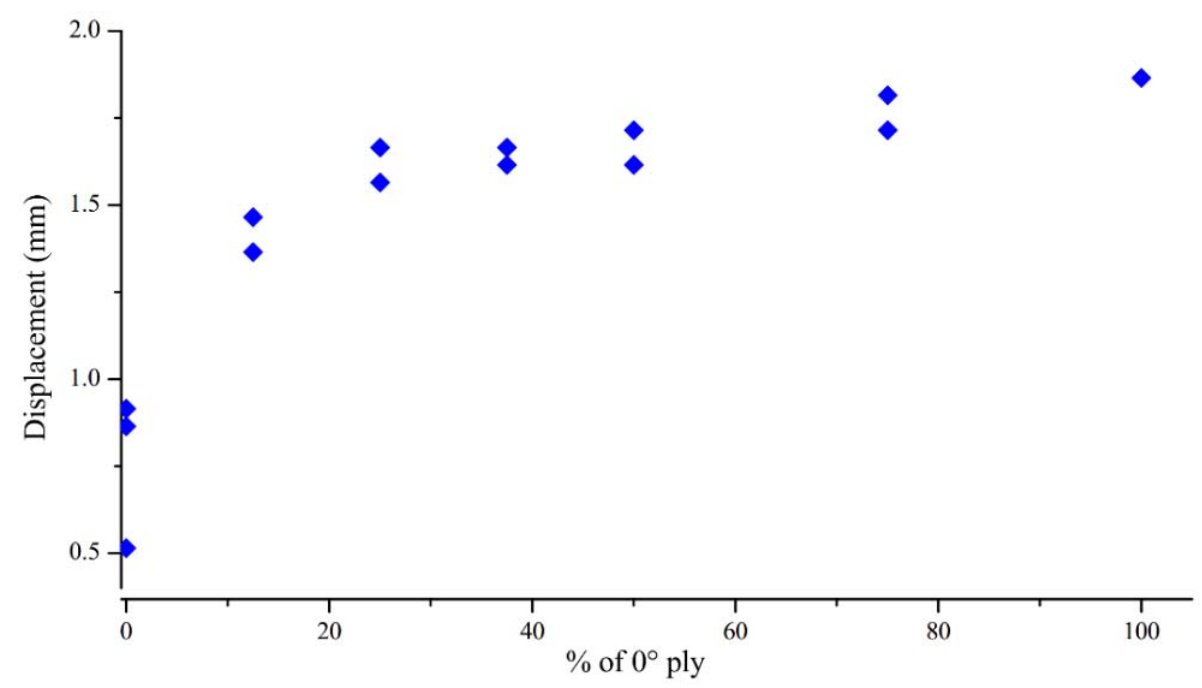

Fig.7. Variation of displacement at failure with $\%$ of $0^{\circ}$ laminas.

The plot of failure load vs deflection shows a general trend, i.e., the deflection value decreases when failure load decreases (Fig.8). But for laminate L7 and L15 the graph shows comparatively higher deflection value because of a high amount of $90^{\circ}$ ply count.

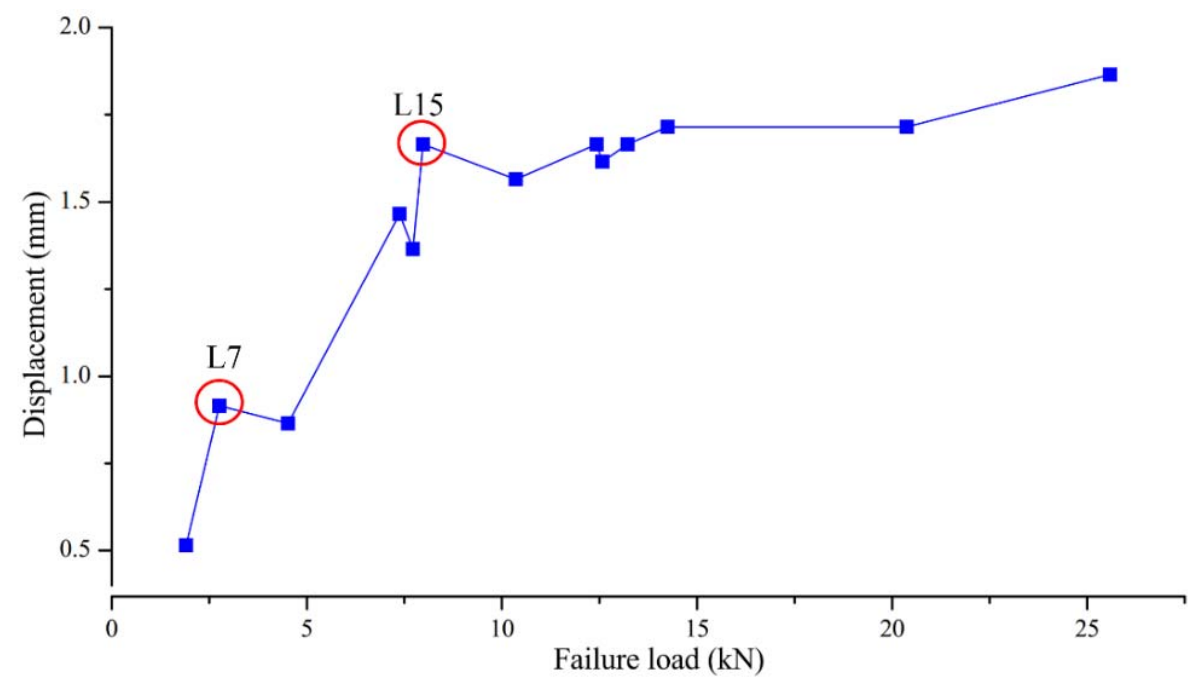

Fig.8. Plot of displacement vs failure load of the laminates.

It can be noted that both the laminates L7 and L15 have $75 \%$ of $90^{\circ}$ laminas. This figure also shows that, displacement reaches almost a constant level of $1.6 \mathrm{~mm}$ to $1.9 \mathrm{~mm}$, when the failure loads are more than approximately $10 \mathrm{kN}$.

Figures 9 and 10 show the propagation of damage for different laminates considering combined effect of all types of failures. For a laminate, the damage state for three different stages is shown: one at the initiation, another at the mid stage and the last one at the time of failure. For all the laminates, damage initiates near the 
hole periphery and propagates gradually to the edges, which causes failure of the whole laminate. It may also be observed that the damage starts to propagate approximately parallel to the fiber orientation as expected. For that reason, for the unidirectional laminate $\mathrm{L} 1,\left[0_{16}\right]$, the damage has started from four points adjacent to the periphery of the hole and started to propagate along $0^{\circ}$ and finally reached the edges by changing the angle very slowly as shown in Fig.9a. For this reason, the path of damage propagation is very long for this laminate and consequently displacement at failure as well as the failure load are also high for this laminate.
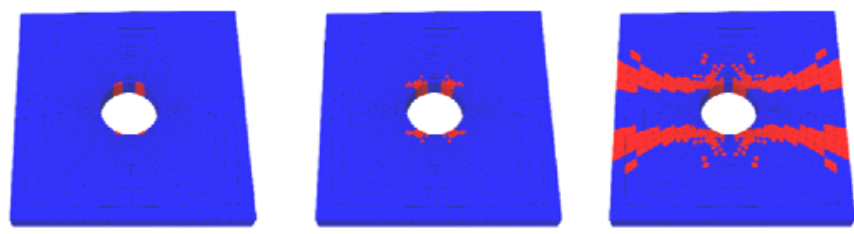

(a) Laminate L1, $\left|0_{16}\right|$
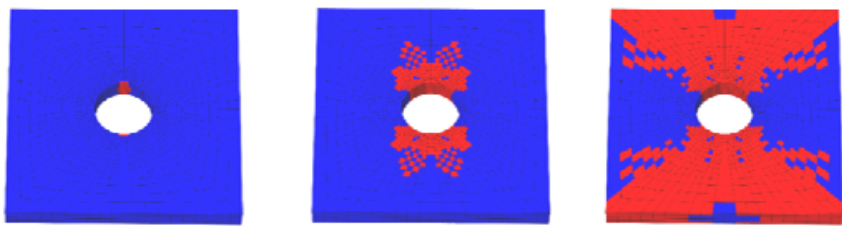

(b) Laminate L2, [9016]
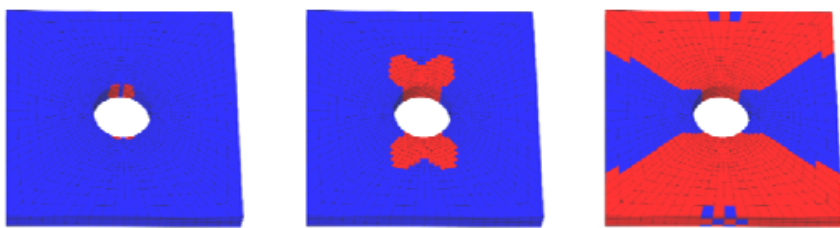

(c) I aminate I. $3,[+45 /-45]_{2 \mathrm{~s}}$

Fig.9. Propagation of damage for the unidirectional laminates and laminate with $\pm 45^{\circ}$ ply.
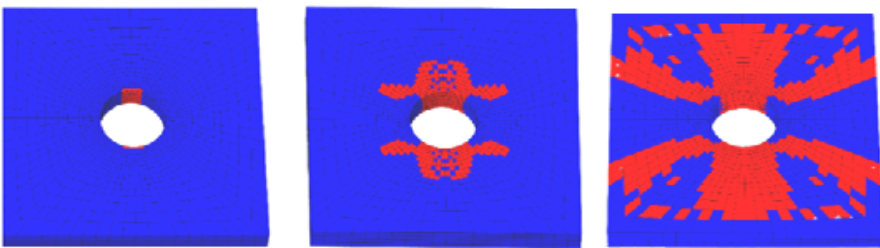

(a) Cross-ply laminate $\mathrm{I} / \mathrm{A},\left[0 / 90 / 90 /\left.0\right|_{2 \mathrm{~s}}\right.$
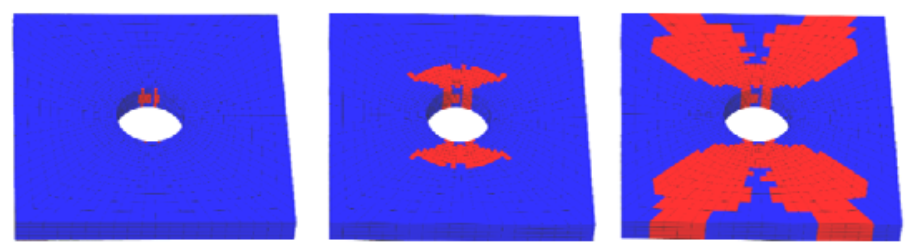

(b) Quasi-isotropic laminate L8. $|0 / 45 / 90 /-45|_{29}$
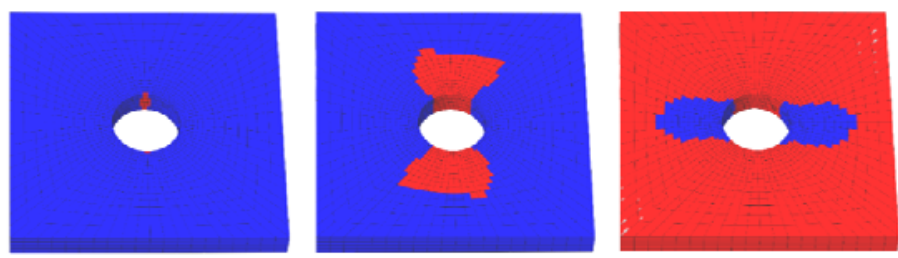

(c) Laminalc L $15,\left[45 / 90_{3}\right]_{2}$

Fig.10. Propagation of damage for the (a) cross-ply laminate L4, $[0 / 90 / 90 / 0]_{2 \mathrm{~s}}$ (b) quasi-isotropic laminate L8, $[0 / 45 / 90 /-45]_{2 s}$ and (c) laminate L15, $\left[45 / 90_{3}\right]_{2 \mathrm{~s}}$ 
On the other hand, for the unidirectional laminate L2, [90 6 , the damage started from two points at hole vicinity and continued to propagate along $90^{\circ}$, as shown in Fig.9b. Due to damage propagation along $90^{\circ}$, damage reaches the edges very fast and consequently the damage propagation path is shortest for this laminate. So, the displacement at failure and failure load are also lowest for this laminate. Similarly, for other laminates, the damage propagates along different angles according to the lamination angles. The crack path in experiment generally shows a very sharp crack for the plates with isotropic material property. But, for laminated composite materials, the crack path is not that much sharp especially when loading is applied very slowly. This can also be noticed from these figures.

The plots of different types of damage individually are presented in Fig.11 for the laminate L15. For the uniaxial tensile loading, damage variables due to compressive fiber/matrix damage are not predominant and hence not shown here. Also, damage due to fiber/matrix shear failure and delamination failure is found to be nominal. Because for the loading type considered here, all the laminates mainly fail due to tensile fiber damage, except laminate L2, [90 16 , where all the fibres are perpendicular to the loading direction. From the damage plot Fig.11a, it can be noticed that tensile fiber damage initiates near the hole and propagates to the edges. Also, for the tensile damage of fiber, damage propagates approximately parallel to the fiber orientation and for this reason the tensile fiber damage pattern is inclined to an angle about $45^{\circ}$ due to the presence of $45^{\circ}$ laminas in L15 laminate. Delamination damage has been noticed near the edge of the laminate as shown in Fig.11c.

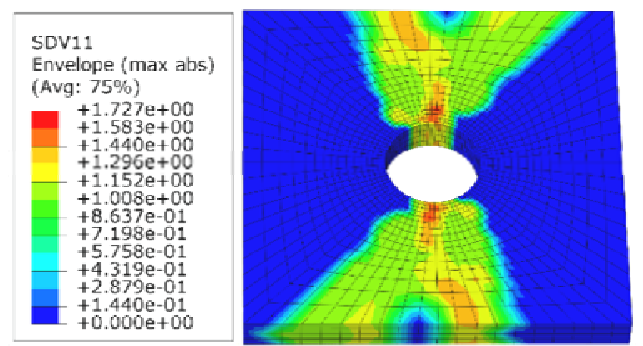

(a) Tensile fibre damage

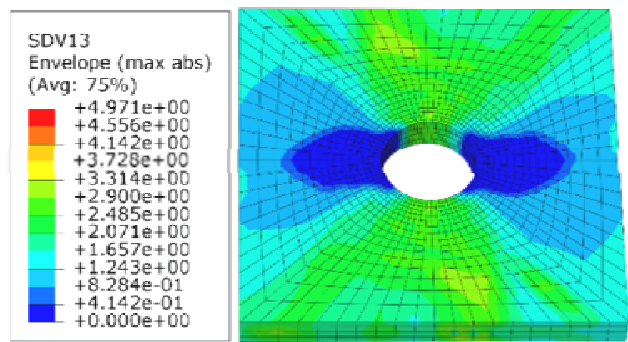

(b) Tensile Matrix damage

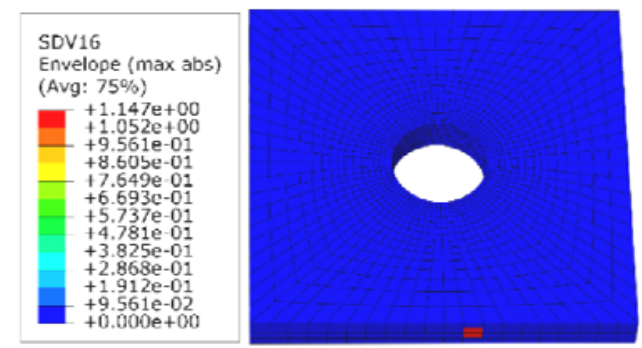

(c) Delamination damage

Fig.11. Plot of different types of damage for laminate L15, $\left[45 / 90_{3}\right]_{2 \mathrm{~s}}$

\section{Conclusions}

In this paper, a three dimensional (3D) finite element progressive damage model has been presented, which can predict the failure load of notched laminated composite plates. The material constitutive relations and the progressive damage algorithms are implemented into the finite element code ABAQUS, using userdefined subroutine UMAT. Six failure modes such as: fiber tension, fiber compression, matrix tension, matrix compression, fiber/matrix shearing and delamination failure have been considered in the present model. The existing failure criteria available in the literature for composite laminates have been modified to include the fiber/matrix shear damage and delamination effects. Due to the use of 3D solid elements, the proposed model can be used for thin as well as thick composite laminates. The numerical progressive damage model presented 
in this paper is also much simpler to implement than other existing damage models and the simulated results agree well with the available experiential and numerical results in the literature.

To observe the effect of the lamination scheme on progressive damage of notched composite laminates, a parametric study has been carried out considering various lamination schemes. From the parametric study, it has been noticed that for unidirectional loading, the failure load greatly depends on $\%$ of fiber parallel to the loading direction. Another noticeable finding is that the displacement at failure does not depend too much on the lamination scheme as compared to the failure load when there are about $25 \%$ of laminas with fibers in the loading direction.

\section{Nomenclature}

[C] - elastic constitutive matrix

$c$ - reduction factor

$D$ - diameter of plate hole

$E$ - Young's modulus of elasticity

$G$ - shear modulus

$L$ - laminate length

$S$ - shear strength

$t$ - laminate thickness

$W$ - laminate width

$X_{c}$ - longitudinal compressive strength

$X_{t}$ - longitudinal tensile strength

$Y_{c}$ - transverse compressive strength

$Y_{t}$ - transverse tensile strength

$Z_{r}$ - strength in ply stack direction

$v$-Poisson's ratio

$\sigma-$ stress

\section{References}

[1] Chang F.K. and Chang K.Y. (1987): A progressive damage model for laminated composites containing stress concentrations. - J. Compos. Mater., vol.21, No.9, pp.834-855.

[2] Icten B.M. and Karakuzu R. (2002): Progressive failure analysis of pin-loaded carbon - epoxy woven composite plates. - Compos. Sci. Technol., vol.62, No.9, pp.1259-1271.

[3] Chang F.K. and Lessard L.B. (1991): Damage tolerance of laminated composites containing an open hole and subjected to compressive loadings: part I - analysis. - J. Compos. Mater., vol.25, No.1, pp.2-43.

[4] Lessard L.B. and Shokrieh M.M. (1995): Two-dimensional modeling of composite pinned-joint failure. - J. Compos. Mater., vol.29, No.5, pp. 671-697.

[5] Shahid I. and Chang F.K. (1995): An accumulative damage model for tensile and shear failures of laminated composite plates. - J. Compos. Mater., vol.29, No.7, pp.926-981.

[6] Su Z.C., Tay T.E., Ridha M. and Chen B.Y. (2015): Progressive damage modeling of open-hole composite laminates under compression. - Compos. Struct., vol.122, pp.507-517.

[7] Kwon Y.W. and Liu C.T. (1997): Study of damage evolution in composites using damage mechanics and micromechanics. - Compos. Struct., vol.38, No.1-4, pp.133-139.

[8] Camanho P.P., Maimí P. and Dávila C.G. (2007): Prediction of size effects in notched laminates using continuum damage mechanics. - Compos. Sci. Technol., vol.67, No.13, pp.2715-2727.

[9] Liu P.F. and Zheng J.Y. (2008): Progressive failure analysis of carbon fiber/epoxy composite laminates using 
continuum damage mechanics. - Mater. Sci. Eng. A., vol.485, No.1-2, pp.711-717.

[10] Sosa J.C., Phaneendra S. and Munoz J. (2012): Modelling of mixed damage on fibre reinforced composite laminates subjected to low velocity impact. - Int. J. Damage Mech., vol.22, No.3, pp.1-19.

[11] Dassault Systemes Simulia Corp. (2012): Abaqus 6.12 analysis user's manual. - Dassault Systemes Simulia Corp., Providence, RI, USA.

[12] Hashin Z. (1980): Failure criteria for unidirectional fibre composites. - J. Appl. Mech., vol.47, No.2, pp.329-334.

[13] Naderi M. and Maligno A.R. (2012): Fatigue life prediction of carbon/epoxy laminates by stochastic numerical simulation. - Compos. Struct., vol.94, No.3, pp.1052-1059.

[14] Reddy Y.S.N., Moorthy C.M.D. and Reddy J.N. (1995): Non-linear progressive failure analysis of laminated composite plates. - Int. J. Non. Linear. Mech., vol.30, No.5, pp.629-649.

[15] Chen J.F., Morozov E.V. and Shankar K. (2014): Simulating progressive failure of composite laminates including in-ply and delamination damage effects. - Compos. Part A Appl. Sci. Manuf., vol.61, pp.185-200.

[16] Lian W. and Yao W. (2010): Fatigue life prediction of composite laminates by FEA simulation method. - Int. J. Fatigue., vol.32, No.1, pp.123-133.

Received: May 11, 2016

Revised: February 8, 2017 